\title{
Carlos de Oliveira e os contos tradicionais portugueses
}

\author{
Maria Cecília de Salles Freire César ${ }^{1}$
}

RESUMO: Este trabalho visa a comparar o capítulo XIX do romance Casa na Duna, de Carlos de Oliveira, com suas matrizes populares (dois contos tradicionais portugueses: "O cego e o mealheiro" e "As barras de ouro") e uma glosa culta (o conto "O Tesouro" de Eça de Queirós). O aspecto analisado centra-se no episódio da panela de ouro no romance de Carlos de Oliveira, cujo tema, a cobiça, suscitou, ao longo da tradição literária, uma série de releituras.

ABSTRACT: The aim of this work is to compare the chapter XIX of the novel Casa na Duna, by Carlos de Oliveira, with its main popular origins (two traditional Portuguese short stories: "O cego e o mealheiro" and "As barras de ouro"), together with another refined interpretation (the short story "O Tesouro", by Eça de Queirós). The aspect analyzed focalizes on the episode of the golden pan in the Carlos Oliveira's novel, whose theme, the avarice, has roused several re-readings throughout the literary tradition.

PALAVRAS-CHAVES: Cultura oral, literatura; folclore; conto popular.

KEYWORDS: Oral culture, literature; folklore; popular tale.

$\mathrm{Na}$ arquitetura ficcional de Carlos de Oliveira, cada capítulo, se analisado isoladamente, tem a estrutura de uma mininarrativa, unidade ao mesmo tempo integrada ao todo do romance e autônoma em sua singularidade ou até exemplaridade, se a associarmos a uma das características principais dos contos tradicionais ${ }^{2}$.

Nesses miniepisódios, constatam-se as características normalmente atribuídas aos contos, quais sejam, a linearidade e a concentração, que combinam com o estilo enxuto de Carlos de Oliveira. Essa redução leva em muitos casos à tensão temporal em que a ação freqüentemente se desenrola: em algumas horas ou até minutos. Com o conto popular ${ }^{3}$, os capítulos dos romances de Carlos Oliveira compartilham muitas vezes o número reduzido

${ }^{1}$ Doutoranda em Estudos Comparados de Literaturas de Língua Portuguesa, FFLCH-USP. Pesquisa: $O$ estudo das representações populares na obra de Carlos de Oliveira. E-mail: mcsfc@uol.com.br

${ }^{2}$ Maria Emília Santos Zacari, em sua Dissertação de Mestrado (Reflexões sobre o foco narrativo em três romances de Carlos de Oliveira), denomina esses episódios como "histórias que o povo conta": "Trata-se da inserção de micro-narrativas, de caráter fantasioso e, ou, do domínio do fantástico, que se espalham entre o povo, sem que se possa explicá-las plenamente. Desprovidas de um nexo sintático com o restante da narrativa, mantêm todavia com ela um nexo semântico, denunciando o espírito simultaneamente mítico e socialmente alienado do homem rural português." (1992,p. 84) Essa é certamente uma característica do povo português que se estende a todas as populações rurais do planeta: são os famosos "causos".

${ }^{3}$ A esse respeito, conferir os verbetes conto e conto popular, do Dicionário de Narratologia de Carlos de Oliveira e A. Cristina M. Lopes. 4 ed. Coimbra:Almedina, 1994, p. 75-83. 
de personagens escassamente caracterizados, correspondendo a tipos, que contrastam com os perfis complexamente construídos das personagens centrais. Essas personagens-tipo, no geral, atuam apenas como suporte de alguma ação "bastante concentrada em torno de uma peripécia particular.”(REIS, 1994, p. 677-682) São as condições que vinculam esse gênero às suas raízes orais.

É o caso, por exemplo, do capítulo XIX de Casa na Duna (OLIVEIRA, 1992, p.677-682) que trata do episódio da panela de ouro encontrada nas terras do comerciante Miranda por um de seus trabalhadores, de nome Tendeiro ${ }^{4}$. Esse capítulo tem sua inspiração em toda uma tradição mítico-religiosa-popular ${ }^{5}$ que, na coletânea de Carlos de Oliveira e José Gomes Ferreira, encontra duas versões populares nos contos "O cego e o mealheiro" (p. 117-118, v. 1) e “As barras de ouro" (p. 340-342, v. 1). Há uma outra versão nas Glosas Cultas dos Temas Populares: “O Tesouro" (p. 499-504), conto de Eça de Queirós sobre o mesmo tema: a cobiça.

O episódio, que não ocupa mais do que três páginas de Casa na Duna, ocorre logo depois do que trata da "aparição dos matos" e parte, assim como o anterior, de um boato, dessa vez sobre a existência de tesouros escondidos da época de Napoleão Bonaparte. Ao mandar os jornaleiros escavarem a terra, Miranda presencia então um deles - o Tendeiro - a anunciar: "Estou rico, estou podre de rico, estou milionário." (p. 677) O que se segue daí é, como se poderia prever, uma disputa a respeito da posse de tal panela. $\mathrm{O}$ dono das terras já tendo se mostrado, em outros episódios, usurpador e avarento - naturalmente assume-se como merecedor de toda a fortuna, reservando ao empregado apenas uma "mancheia". A querela termina com a tentativa de assassinato (por estrangulamento) do patrão, salvo a tempo por outros empregados.

Ao incorporar esse episódio ao romance, Carlos de Oliveira dá destaque a uma situação que permeia não só esse, como outros romances do autor: a disputa pela riqueza alheia. O conflito central de Alcateia, por exemplo, origina-se daí: quem ficaria com as terras dos bandido Lourenção, que não deixara herdeiros, após sua morte? Em Casa na Duna apresenta-se o problema nas várias instâncias da narrativa, das personagens centrais

\footnotetext{
${ }^{4}$ Note-se que "tendeiro" é um dos nomes populares do diabo.

${ }^{5}$ Entre as matrizes desse episódio, Geraldo Nogueira de Amorim (Usina e Casa na Duna: Fronteiras Culturais e Literárias. São Paulo:USP. Tese de Doutoramento, 2003) cita o mito do rei Midas, o Velocino de ouro, a comédia Aululária (de Plauto), O Avarento (de Molière), O Tesouro do Mujique (recolhido por Propp). Poderia se acrescentar a essa lista também a fábula da "Galinha dos Ovos de Ouro", o conto "As três maçãzinhas de ouro" e a procura do Santo Graal, entre tantas outras fontes que inspiraram os artistas dos mais variados tempos e espaços.
} 
às secundárias: no desejo de Mariano Paulo de se apoderar das terras do Guimarães, na ânsia do comerciante Miranda de abocanhar as lavouras improdutivas dos trabalhadores da Gândara.

O capítulo oscila entre o trágico e o cômico, enfatizando as reações das personagens diante do fato inusitado ocorrido "por uma tarde de sol":

O Tendeiro: “(...) deu um grito, atirou a enxada fora e começou às cambalhotas.”

Miranda: "(...) e o coração bateu-lhe no peito como um sino; ia caindo redondo no chão."

Os camponeses: “(...) continuaram no mesmo sítio, mudos, com os olhos encadeados pelo oiro.” (grifos meus; OLIVEIRA, 1992, p. 677-678)

Diante da intenção do patrão de apoderar-se injustamente de toda a riqueza, o empregado tem uma reação violenta. Cria-se uma atmosfera de tensão que culmina na descrição da grotesca figura do Miranda sendo estrangulado pelo Tendeiro:

Os pinhais, a aldeia, o céu, desapareceram. Ficou apenas à sua frente o pescoço gordo do Miranda. O pescoço engordou mais, e mais, e mais. Deitou-lhe as mãos calosas, apertou. A carne branca, flácida, fez-se vermelha; fez-se roxa; e não chegou a fazer-se negra porque o Tendeiro foi agarrado a tempo. Largou o pescoço do patrão com desgosto e pôs-se a chorar. (OLIVEIRA, 1992, p. 678-679)

Sintetiza-se, nessa cena expressionista, uma raiva ancestral, fruto de séculos de opressão, representada metonimicamente pelo pescoço branco e gordo do patrão. Num contexto em que as personagens estão no limiar da sub-humanidade, ressalta-se, em vez disso, a brutalidade das condições sócio-econômicas.

O que se segue a essa cena é a tentativa de reanimar o Miranda, quebrando, por meio do humor e do coloquialismo dos diálogos, o trágico da situação:

Justino apontou o corpo do Miranda e gracejou:

-Salvámos-lhe a vida, que diabo, sempre temos direito a uma moeda. (...)

O Tendeiro enfiou as libras nos bolsos do colete e indicou o Miranda:

- Se calhar, matei-o.

O Catrouxo pegou outra vez na bilha:

-Descansa que ele ressuscita.

Despejou a água toda, do mais alto que pôde, e o Miranda estremeceu. Daí a nada abria os olhos, devagar. Os jornaleiros consolaram-no:

- Vá lá que andou com sorte. O tipo ia-lhe dando cabo do canastro. (OLIVEIRA, 1992, p. 679) 
E, por fim, a repercussão da descoberta:

A notícia correu. O chão da gândara, bastava esgaravatar no sítio certo e aí estavam as minas ao sol. Pesquisadores surgiram dum instante para o outro, cavando noite e dia, revolvendo o areeiro. A bruxa do Albocaz sugerira os poços, as paredes velhas, como esconderijos:

- Procurem nas rachas dos adobos. (OLIVEIRA, 1992, p. 680)

Comparece nesse episódio outra das tantas figuras do imaginário popular: a bruxa de Albocaz, adaptada, como sempre, ao contexto rural da Gândara, com suas areias e casas de adobe, tão bem descritas e fotografadas no estudo de Vital Moreira: “É essencialmente camponês o universo ficcional de Carlos de Oliveira. Assim era na realidade o mundo gandarês nos meados do século passado.”(MOREIRA, 2003) Essa figura soma-se a tantas outras em suas obras, além da já citada personagem do Lobisomem: a doida de Fonterrada (Alcateia), o bruxo dos Moirões (Pequenos Burgueses), os quadrilheiros e vagabundos (representados por João Santeiro e seus sequazes de Alcateia), todos eles figuras arquetípicas e ao mesmo tempo tipicamente portuguesas em suas caracterizações.

Entrelaçam-se, portanto, nesse episódio, o anedótico, o maravilhoso e o moral, as três vertentes do conto popular e folclórico. Certamente se classificará como humorística não só a procura pelo ouro empreendida pelos pesquisadores (e até mesmo pelo Lobisomem, que, com tal objetivo, pede a enxada a Mariano Paulo) como também o final do capítulo que enfoca a convalescença do Miranda, examinando, fascinado, sua riqueza:

O Miranda convalescia. Sentava-se na cama e ordenava à mulher:

- O baú para aqui.

Mexia e remexia as libras, pegava nelas, atirava-as nos ar, deixava-as cair no cobertor. O cintilar rumoroso das moedas fascinava-o. Depois, contava-as cuidadosamente e propunha:

- Vê lá se acertas quantas são.

A mulher fitava aquele fulgor e arriscava:

- Talvez um cento, talvez mais.

O Miranda sorria:

- Nem tanto, alma de Deus. Corta-lhe um pouco e torna a dizer. (OLIVEIRA, 1992, p. 681-682)

No que se refere ao desfecho moral, próprio dos contos exemplares, o que se nota, no capítulo em questão, é a inversão irônica da sentença, já que é o padre Alípio, típico representante do comprometimento da Igreja com o poder econômico, quem aconselha: “- 
Se houver ouro na terra, deixem onde está. Quero almas limpas de cobiça. O verdadeiro ouro é Cristo.” (Oliveira, 1992, p. 682)

Confronte-se esse final com o conto "O Inferno", versão tirada de Ataíde de Oliveira, que apresenta dois sujeitos que encontram um saco de dinheiro e, na disputa pela riqueza, terminam mutuamente assassinados. Antes, haviam sido advertidos por Cristo: "Não vão por essa estrada que vai parar no inferno.", mensagem que, no final, se confirma com a lição: "E assim se realizou a profecia do Divino Mestre: ambos caíram no inferno da ambição.” (Oliveira, 1992, v. 1, p. 50)

Verifica-se desse cotejo que, enquanto o conto popular valoriza a sabedoria cristã a partir de seu primeiro Mestre, Jesus Cristo, o texto literário insinua o desvirtuamento dessa sabedoria, ao colocá-la na boca de um mensageiro do Mestre, padre Alípio, que, sendo representante de uma instituição que deveria sustentá-la, em vez disso a deturpa, ao fechar os olhos para a desigualdade na distribuição da riqueza. A mensagem cristã se inverte na medida em que seu porta-voz revela-se esvaziado de credibilidade.

Em Alcateia já tinha ficado explícito o conluio entre o poder político, encarnado no Administrador de São Caetano, e o religioso, na figura do padre Silva, que antes havia se aliado a um pretendente desse poder: Cosme Sapo. Se Tendeiro é a alcunha popular do diabo, só se pode concluir então que ele é um pobre-diabo, como muitos da tradição popular, o principal prejudicado no episódio da panela de ouro, que não só teve de abrir mão da riqueza que havia encontrado, como teve de fugir, fadado a cumprir a sina dos forada-lei, a mesma de Leandro e Troncho (Alcateia), apesar de terem cumprido a pena na prisão. (Diante da falta de saídas para a sobrevivência, os dois voltam a praticar roubos e, se o Tendeiro tivesse aparecido em outro romance de Carlos de Oliveira, como ocorre com alguns habitantes desse contexto gandarês, certamente o veríamos traçando esse mesmo destino.)

O conto "O Tesouro", de Eça de Queirós, apresenta outra versão desse episódio, com as típicas características das glosas cultas: rica caracterização das personagens e do ambiente e elaboração primorosa dos recursos de linguagem. Nessa versão, são três irmãos ${ }^{6}$ nobres arruinados (e não “dois sujeitos”, como no conto popular), que encontram o tesouro (Guanes, Rui e Rostabal), riqueza esta que “(...) ainda lá está, na mata de Roquelanes”,

\footnotetext{
${ }^{6}$ Deve-se lembrar a carga simbólica do número três nos contos populares. Nesse conto, esse número reitera-se nas três fechaduras, o que condiciona sua abertura pelos três irmãos em conjunto, nos três alforges de couro, nas três maquias de cevada, nos três empadões de carne e nas três botelhas de vinho.
} 
metaforizando a atualidade da lenda, que o narrador localiza num distante "Reino das Astúrias" (que se associa a um apagado dístico em letras árabes sobre a tampa do tesouro).

Além da simbologia presente no número três, o autor explora os significados de Inverno, Primavera e Domingo presentes no texto, marcas temporais que expressam a passagem (tornada impossível) da degradação (em que viviam os irmãos) à sublimação (por meio do ouro, que remete à perfeição) da água (símbolo da vida) e da $c r u z^{7}$ (referência às mortes).

O ponto em comum entre o conto de Eça e o conto popular reside justamente na emboscada armada pelas personagens que acaba por resultar na morte de todos. Em "O Inferno", os dois personagens morrem envenenados pelo vinho, após terem combinado que um deles iria atrás de uma cavalgadura para transportar os valores. Em "O Tesouro", farto em detalhes, o irmão que havia saído em busca de alimento é morto a golpe de espada pelo segundo, que, ao lavar o rosto na água de uma fonte, é apunhalado pelo terceiro, vindo este a morrer envenenado pelo vinho trazido pelo primeiro. Entre a primeira e a segunda mortes, a ação é narrada com tamanha riqueza de pormenores e atinge tal ponto de tensão, quase tornando isocrônico o tempo do discurso do tempo do conflito, que o leitor é praticamente trazido ao centro da tragédia.

Se no filão popular e no literário o motivo central é o mesmo, os dois diferem radicalmente na maneira de destrinçar o fio narrativo, estando o capítulo de Carlos de Oliveira no meio-termo entre essas duas técnicas.

Para finalizar, vale uma menção aos dois outros contos incluídos na coletânea de Carlos de Oliveira e José Gomes Ferreira: "O Cego e o Mealheiro" e "As Barras de Ouro", valendo frisar que o tema da cobiça ou da procura pela riqueza permeia grande parcela da antologia.

No primeiro deles, explora-se o aspecto do logro: um cego, que ocultara uma panela com moedas de ouro em seu quintal, desconfia do vizinho como autor do furto de sua riqueza. Para recuperá-la, engana-o, dizendo que deixaria toda a sua fortuna a ele e iria acrescentar mais peças no buraco onde havia enterrado o tesouro. O vizinho, então, cai no logro e devolve a panela, para ver se apanhava o resto das peças, fazendo com que o cego

${ }^{7}$ A cruz está presente na cantiga entoada duas vezes por um dos irmãos ("Olé! Olé! / Sabe la cruz de la iglesia, / Toda vestida de negro...”) que funciona como índice antecipador (prolepse, na terminologia de G. Genette, cf. nota ....do cap.... deste trabalho) das mortes que virão, confirmando a intricada elaboração dos elementos da narrativa nesse conto. 
recupere a riqueza, comprovando a idéia de que a cegueira está relacionada, muitas vezes, à sagacidade. No segundo, o destaque é dado ao maravilhoso: três irmãos fazem, cada um deles, que três tições de carvão transformem-se em três barras de ouro ao longo de três dias consecutivos (novamente o número três!). Ficam ricos e vão viver na cidade, num rico palácio. Quando, um dia, um mendigo passou pela porta e pediu esmola, mandaram-no entrar e deram-lhe comida; a seguir, o mendigo deu graças a Deus e todo o palácio desapareceu. Dessa vez, a posse da riqueza não se associa à mesquinharia, avareza ou vingança, como nos outros exemplos, mas sim ao caráter ilusório da riqueza que está presente em todos eles.

O ouro, quer estando oculto ou não, suscitando a cobiça ou não, pode também abrir para a idéia, como sugere Silvina Rodrigues Lopes (LOPES, 1996), da busca da interioridade, "impondo-se como imagem da origem da verdade no processo de conhecimento;ou simplesmente servindo de suporte da ilusão ou esperança dos que nada têm.” Tal processo está na essência da busca alquímica da purificação da alma (simbolizada pelo ouro), busca essa que na maioria das vezes não se completa por causa da ambição que aprisiona o homem ao mundo terreno, como comprovam os textos que serviram de exemplo para ilustrar essa tese.

\section{Referências bibliográficas}

AMORIM, Geraldo Nogueira de. Usina e Casa na Duna: Fronteiras Culturais e Literárias. São Paulo:USP. Tese de Doutoramento, 2003.

LOPES. Silvina Rodrigues. Carlos de Oliveira - O Testemunho Inadiável. Sintra:Gráfica Europam, Lda, 1996.

MOREIRA, Vital. Paisagem Povoada: a Gândara na Obra de Carlos de Oliveira. Coimbra:Imprensa de Coimbra, Lda, 2003.

OLIVEIRA, Carlos de. Obras de Carlos de Oliveira. Lisboa: Caminho, 1992. . Alcateia. Lisboa: Coimbra Editora Lda, 1945.

Pequenos Burgueses. 1 ed. Coimbra:Coimbra Editora, Lda, 1948.

OLIVEIRA, Carlos de \& FERREIRA, José Gomes. Contos Tradicionais Portugueses. Lisboa: Iniciativas Editoriais, 1958, v. 1 e 2.

REIS, Carlos \& LOPES, A. Cristina M. Dicionário de Narratologia. 4 ed., Coimbra:Almedina, 1994.

ZACARI, Maria Emília Santos. Reflexões sobre o foco narrativo em três romances de Carlos de Oliveira. São Paulo:USP, Dissertação de Mestrado, 1992. 